\title{
Nonfasting triglycerides and risk of cardiovascular death in men and women from the Norwegian Counties Study
}

\author{
Anja S. Lindman • M. B. Veierød • A. Tverdal • \\ J. I. Pedersen $\cdot$ R. Selmer
}

Received: 1 February 2010/Accepted: 23 August 2010/Published online: 2 October 2010

(C) The Author(s) 2010. This article is published with open access at Springerlink.com

\begin{abstract}
The association between nonfasting triglycerides and cardiovascular disease (CVD) has recently been actualized. The aim of the present study was to investigate nonfasting triglycerides as a predictor of CVD mortality in men and women. A total of 86,261 participants in the Norwegian Counties Study 1974-2007, initially aged 20-50 years and
\end{abstract}

Anja S. Lindman's former affiliation is Norwegian Institute of Public Health, Norway and Department of Biostatistics, Institute of Basic Medical Sciences, University of Oslo, Norway

A. S. Lindman $\cdot$ A. Tverdal $\cdot$ R. Selmer

Division of Epidemiology, Norwegian Institute of Public Health, Oslo, Norway

A. Tverdal

e-mail: aage.tverdal@fhi.no

R. Selmer

e-mail: randi.Selmer@fhi.no

A. S. Lindman - M. B. Veierød

Department of Biostatistics, Institute of Basic Medical Sciences,

University of Oslo, Oslo, Norway

M. B. Veierød

e-mail: marit.veierod@basalmed.uio.no

M. B. Veierød · J. I. Pedersen

Department of Nutrition, Institute of Basic Medical Sciences,

University of Oslo, Oslo, Norway

J. I. Pedersen

e-mail: j.i.pedersen@medisin.uio.no

Present Address:

A. S. Lindman $(\bowtie)$

Norwegian Knowledge Centre for the Health Services, PB 7004,

St Olavs plass, 0130 Oslo, Norway

e-mail: Anja.Schou.Lindman@kunnskapssenteret.no free of CVD were included. We estimated hazard ratios (HRs) for deaths from CVD, ischemic heart disease (IHD), stroke and all causes by level of nonfasting triglycerides. Mean follow-up was 27.0 years. A total of 9,528 men died (3,620 from CVD, 2,408 IHD, 543 stroke), and totally 5,267 women died (1,296 CVD, 626 IHD, 360 stroke). After adjustment for CVD risk factors other than HDL-cholesterol, the HRs $(95 \% \mathrm{CI})$ per $1 \mathrm{mmol} / \mathrm{l}$ increase in nonfasting triglycerides were 1.16 (1.13-1.20), 1.20 (1.14-1.27), $1.26(1.19-1.34)$ and 1.09 (0.96-1.23) for all cause mortality, CVD, IHD, and stroke mortality in women. Corresponding figures in men were 1.03 (1.01-1.04), 1.03 (1.00-1.05), $1.03(1.00-1.06)$ and 0.99 (0.92-1.07). In a subsample where HDL-cholesterol was measured $(n=40,144)$, the association between CVD mortality and triglycerides observed in women disappeared after adjustment for HDL-cholesterol. In a model including the Framingham CHD risk score the effect of triglycerides disappeared in both men and women. In conclusion, nonfasting triglycerides were associated with increased risk of CVD death for both women and men. Adjustment for major cardiovascular risk factors, however, attenuated the effect. Nonfasting triglycerides added no predictive information on CVD mortality beyond the Framingham CHD risk score in men and women.

Keywords Triglycerides - Cardiovascular disease . Mortality $\cdot$ Nonfasting $\cdot$ Cohort study
Abbreviations
BMI Body mass index
CHD Coronary heart disease
CVD Cardiovascular disease
HR Hazard ratio
IHD Ischemic heart disease
MI Myocardial infarction 


\section{Introduction}

Blood samples for measurements of triglyceride levels are typically obtained in the fasting state, and increased levels of fasting triglycerides have been associated with increased risk of cardiovascular disease (CVD) in a number of studies [1-4]. Atherosclerosis is suggested to be a postprandial phenomenon [5, 6]. Recent prospective cohort studies suggest that the association with coronary heart disease (CHD) is stronger for nonfasting than fasting triglycerides [7, 8], and possibly also for stroke [9]. In the Women's Health Study, nonfasting triglycerides were associated with incident cardiovascular events, independent of other risk factors, lipids, and markers of insulin resistance, whereas weaker associations were found for fasting levels [7]. The associations were particularly strong for samples drawn 2-4 h after meals. This corresponds to peak levels of triglycerides and remnant particles at $4 \mathrm{~h}$ after meal consumption, with a gradually decline thereafter [8]. Elevated levels of postprandial triglycerides may indicate a high content of remnant lipoproteins derived from triglyceride rich chylomicrons [5]. Remnant lipoproteins can enter the arterial wall, and contribute to the formation of foam cells and thus cause atherosclerosis [10]. Measurements in the postprandial state include these remnant lipoproteins.

The associations between triglycerides and cardiovascular risk have been reported to be stronger in women than in men in both fasting and nonfasting states [1, 8]. The Norwegian Counties Study is a prospective cohort study comprising three consecutive cardiovascular screenings performed between 1974 and 1988 in three Norwegian counties including over 90,000 individuals. Two earlier papers from this cohort study (in 1989 and 1993), found nonfasting triglycerides to be an independent risk factor for cardiovascular death in women [11], but not in men [12]. These papers had short follow-up, and used data only from the first screening. With additional data from the two latter screenings and a substantially longer follow-up, we study the association between nonfasting levels of triglycerides and cardiovascular mortality risk, including stroke, in this large cohort of women and men. In a subsample from the second screening, we also study the effect of adjustment for HDL-cholesterol and Framingham risk score.

\section{Methods}

The Norwegian Counties Study

Three consecutive cardiovascular screenings (screenings I, II, and III) in the three Norwegian counties Oppland, Sogn og Fjordane, and Finnmark, were carried out in 1974-78, 1977-83, and 1985-88, respectively (Fig. 1). A detailed

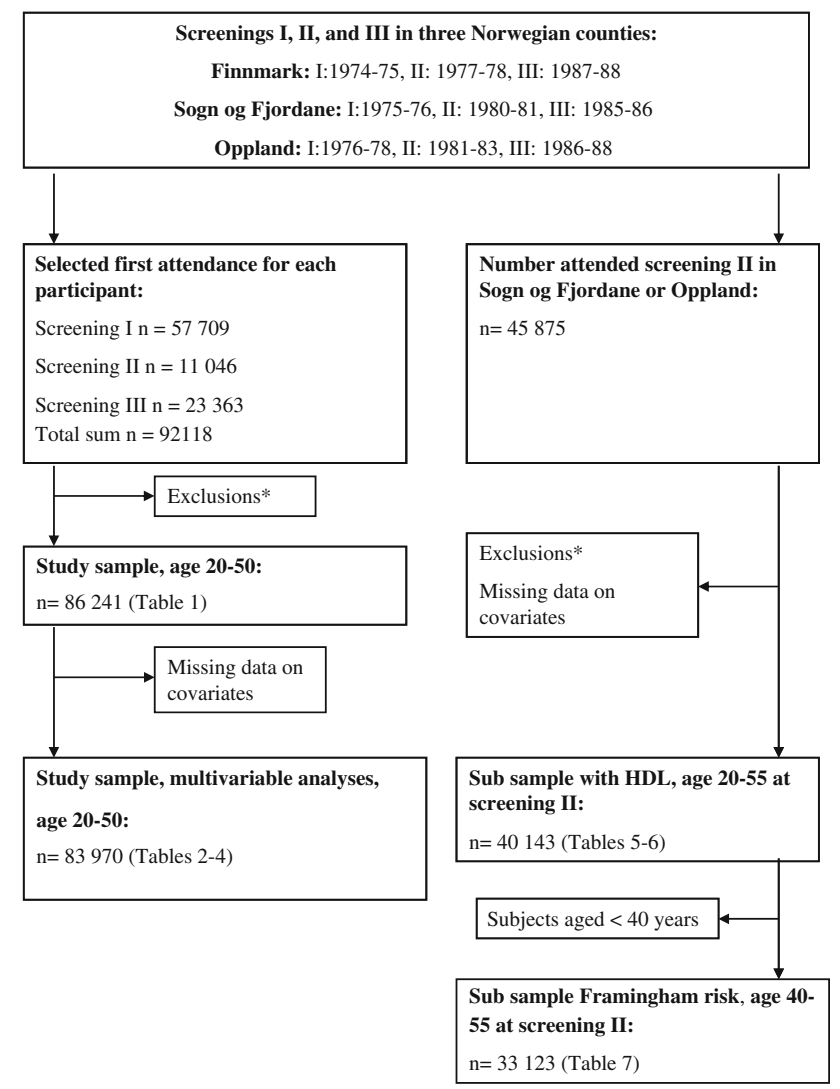

Fig. 1 Flow chart illustrating how study samples were obtained from the three screenings. *Exclusions: Participants reporting a history of myocardial infarction, angina, stroke, diabetes, use of nitroglycerine or blood pressure reducing drugs, outside age range, extreme/missing triglyceride values or incomplete data on observation time

overview of the invited age groups and attendance according to survey and county has previously been described [13]. Briefly, in screening I all residents aged 35-49 years, and a random sample aged 20-34 years, were invited. In screening II, individuals from the previous screening still residing in the county were re-invited, in addition to a random sample aged 20-39 years. All inhabitants aged 40-54 years (40-62 years in Finnmark) and samples of previously invited, were invited to screening III. The attendance at each screening was 88,88 and $84 \%$. The methods and results from the first and second screening have been described in detail [14-16].

\section{Data collection}

Investigations according to standardized methods were carried out by mobile screening teams [14]. All invited persons were asked to fill in the main questionnaire at home and bring it to the screening station. Then, according to the protocol, a trained nurse checked it for omissions and inconsistencies. The questionnaire covered among other things, history of previous cardiovascular disease and 
disease symptoms, current medication (blood pressure lowering or nitroglycerine) level of leisure time physical activity, and smoking habits. Menopause was registered by personal interview. Moreover, a simple clinical examination was performed. Body weight (kilograms) and height $(\mathrm{cm})$ were measured with the participants wearing light clothing without shoes. Body mass index (BMI) was computed as weight $/$ height $^{2}\left(\mathrm{~kg} / \mathrm{m}^{2}\right)$. In screenings I and II, systolic and diastolic blood pressure $(\mathrm{mm} \mathrm{Hg})$ were measured with a mercury sphygmanomenter (ERKA, Kallmeyer Medizintechnik GmbH \& Co KG, Bad Tölz, Germany). Two readings were recorded, and the second was used. A Dinamap 845XT instrument (Criticon Inc., Tampa, Florida, USA) was used at screening III. Three different readings were made with one-minute intervals, and the mean of the two last measurements was used. In all three screenings a nonfasting venous blood sample was drawn. The analyses were performed at the Central Laboratory, Ullevål Hospital, Oslo, Norway. Total cholesterol and triglyceride analyses were carried out in all screenings, whereas HDL-cholesterol was analyzed at screening II only. The HDL-cholesterol measurements for Finnmark were performed in samples that had been frozen, in contrast to samples from Oppland and Sogn og Fjordane, thus only the HDL-cholesterol values from the to latter counties were used in the present study. HDL-cholesterol was analysed by enzymatic methods [17]. For total cholesterol and triglycerides, non-enzymatic methods were used in screening I (all counties). The accuracy of the methods have been described in detail previously $[12,14]$. In screening II, non-enzymatic methods were used on samples from Finnmark, whereas enzymatic methods were used on samples from Sogn og Fjordane and Oppland [17]. Enzymatic methods were used in screening III. Triglycerides and cholesterol values from non-enzymatic analyses were corrected to values compatible with enzymatic methods according to the formulas: Triglyceride (new method) $=0.90 *$ triglyceride (old method) -0.11 and cholesterol $($ new method $)=0.92 *$ cholesterol $($ old method $)+0.03$. The formulas were evolved after an extensive test program comparing the old and new method [16].

\section{Study samples}

For the main analyses in the present study we have used data from the first attendance for each participant, either screenings I, II, or III (Fig. 1). Participants reporting a history of myocardial infarction, angina, stroke, diabetes, or use of nitro-glycerine or blood pressure reducing drugs, were excluded $(n=3,965)$. The analyses were further limited to the age group $20-50$ years $(n=1,850$ excluded), as the majority of the participants were in this age range. Subjects missing triglyceride measurement $(n=42)$, with extreme triglyceride levels (triglycerides $<0.2 \mathrm{mmol} / 1$ or triglycerides $>20 \mathrm{mmol} / \mathrm{l}, n=18$ ) or subjects with incomplete data on observation time $(n=2)$ were excluded, giving a sample of 86,241 participants (42,600 women and 43,641 men), aged 20-50 years and initially free of cardiovascular disease. After further exclusions of records with missing data on covariates, the main study sample consisted of 83,970 participants $(41,317$ women and 42,653 men) (Fig. 1).

To allow for adjustments for HDL-cholesterol, additional analyses were conducted in subjects participating in screening II in Oppland and Sogn og Fjordane. Participants were 5 years older at screening II, thus we included age group 20-55 years. By using the same criteria as for the main study sample described above, 40,143 participants (20,293 women and 19,850 men) free of cardiovascular disease were eligible for these analyses (Fig. 1, sub sample with HDL). Analyses including Framingham risk were restricted to 33,123 participants aged 40-55 years at baseline (16,805 women and 16,318 men) (Fig. 1, sub sample Framingham risk).

\section{Definition of endpoints}

The linkage to the Norwegian Causes of Death Registry was ensured by the unique 11-digit identification number of all Norwegian citizens. This linkage was approved by the Norwegian Data Inspectorate. Deaths were classified according to the 8th, 9th or 10th revision of the International Classification of Disease (ICD). We studied CVD (ICD 8 (1974-1985) codes 390-344.1, 444.3-458, 782.4, ICD 9 (1986-1995) codes 390-459, ICD 10 (1996-) codes I00-199), ischemic heart disease (IHD) (ICD 8-9 codes 410-414, ICD 10 codes I20-I25), stroke (ICD 8-9 codes 430-438, ICD 10 codes I60-I69), and all cause mortality. End of follow-up was 31 December 2007.

\section{Statistical analyses}

Cox proportional hazards regression was applied with attained age as the time scale. The number of person years was calculated from the date of examination to the date of death, emigration or 31.12.2007, whichever came first. Triglycerides were categorized according to quintiles (separately for men and women) and modelled as dummy variables. To test for trend, triglycerides categories were entered as an ordinal variable. We adjusted for known CVD risk factors; total cholesterol, systolic blood pressure, BMI, daily smoking (yes, no), time since last meal (less than $1 \mathrm{~h}, 1-2 \mathrm{~h}, 2-4 \mathrm{~h}, 4 \mathrm{~h}$ or more), leisure time physical activity (sedentary, moderate, intermediate/intensive), and menopausal status for women (yes, no). The upper two categories for time since last meal and physical activity were collapsed due to small numbers. Additional 
adjustments for HDL-cholesterol were performed for subjects in the sub-sample from screening II. Furthermore, individual Framingham risk scores were calculated according to Anderson et al. [18] (only for participants $\geq 40$ years), and added as a covariate in the analyses on the sub-sample. Framingham risk score includes the risk factors total cholesterol, HDL-cholesterol, smoking (no, yes), age, systolic blood pressure and diabetes (no, yes). Statistical analyses were performed on subjects with complete information on all covariates.

The proportional hazards assumption was examined by Schoenfeld residuals. We tested interaction effects between triglycerides and gender, time since last meal, cholesterol,
BMI, and smoking, with triglycerides as a continuous variable. The linearity assumption for triglycerides was assessed by comparing adjusted models having only a linear term with models having linear and higher order polynomial terms (quadratic and cubic terms). The likelihood ratio test was used for model comparison.

A total number of 51,931 subjects had measurements of triglycerides both in screenings I and II, approximately 5 years apart. The partial correlation coefficients (R) between the two measurements, adjusted for age, were estimated to 0.50 for men and 0.51 for women. These values can be used to assess regression dilution for ageadjusted hazard ratios [19]. HRs adjusted for regression

Table 1 Baseline [Baseline values are data from first attendance for individuals participating in at least one of the screenings] characteristics of 86,241 participants (42,600 women and 43,641 men) from the Norwegian Counties Study by quintiles of triglycerides in the main study sample (age $20-50$ at baseline)

\begin{tabular}{|c|c|c|c|c|c|c|c|}
\hline & & \multicolumn{5}{|c|}{ Quintile of nonfasting triglycerides } & \multirow[t]{2}{*}{ All } \\
\hline & & 1 & 2 & 3 & 4 & 5 & \\
\hline \multirow{11}{*}{$\begin{array}{l}\text { Women } \\
\text { Triglycerides, } \\
\text { median } \\
(\text { range }) \\
(\mathrm{mmol} / \mathrm{l})\end{array}$} & & $\begin{array}{l}0.66 \\
\quad(0.21-0.79)\end{array}$ & $\begin{array}{l}0.90 \\
\quad(0.80-1.01)\end{array}$ & $\begin{array}{l}1.13 \\
(1.02-1.27)\end{array}$ & $\begin{array}{l}1.46 \\
(1.28-1.70)\end{array}$ & $\begin{array}{l}2.16 \\
\quad(1.71-18.72)\end{array}$ & $\begin{array}{l}1.13 \\
\quad(0.21-18.72)\end{array}$ \\
\hline & No. of participants & 8,585 & 8,303 & 8,576 & 8,654 & 8,482 & 42,600 \\
\hline & Age, mean (SD), year & $37.8(7.1)$ & $39.2(6.9)$ & $39.7(6.8)$ & $40.0(6.9)$ & $40.1(6.7)$ & $39.5(6.9)$ \\
\hline & $\begin{array}{l}\text { Total cholesterol, mean } \\
(\mathrm{SD}) \\
(\mathrm{mmol} / \mathrm{l})\end{array}$ & $5.37(0.96)$ & $5.76(1.01)$ & $5.98(1.10)$ & $6.19(1.14)$ & $6.66(1.34)$ & $5.99(1.20)$ \\
\hline & $\begin{array}{c}\text { Systolic blood pressure, } \\
\text { mean }(\mathrm{SD}),(\mathrm{mm} \mathrm{Hg})\end{array}$ & $125(15)$ & $126(15)$ & $127(16)$ & $129(16)$ & $132(18)$ & $128(16)$ \\
\hline & $\begin{array}{l}\text { Diastolic blood pressure, } \\
\text { mean }(\mathrm{SD}),(\mathrm{mm} \mathrm{Hg})\end{array}$ & $77(8)$ & $78(10)$ & $78(10)$ & $79(11)$ & $81(11)$ & $79(11)$ \\
\hline & BMI, mean (SD), $\left(\mathrm{kg} / \mathrm{m}^{2}\right)$ & $22.8(3.0)$ & $23.4(3.3)$ & $23.9(3.6)$ & $24.4(3.9)$ & $26.0(4.7)$ & $24.1(3.9)$ \\
\hline & Post-menopausal (\%) & 4.1 & 6.3 & 7.5 & 8.9 & 12.3 & 7.8 \\
\hline & Smoking (\%) & 31.8 & 36.9 & 40.5 & 43.0 & 48.4 & 40.1 \\
\hline & Physical inactivity (\%) & 18.1 & 20.3 & 20.5 & 22.2 & 24.8 & 21.8 \\
\hline & $\begin{array}{l}\text { Time since meal, mean } \\
\text { (SD) }\end{array}$ & $2.75(0.99)$ & $2.61(0.98)$ & $2.56(0.97)$ & $2.45(0.95)$ & $2.42(0.93)$ & $2.56(0.97)$ \\
\hline \multirow{10}{*}{$\begin{array}{l}\text { Men } \\
\text { Triglycerides, } \\
\text { median } \\
(\text { range }) \\
(\mathrm{mmol} / \mathrm{l})\end{array}$} & & $\begin{array}{l}0.89 \\
\quad(0.21-1.10)\end{array}$ & $\begin{array}{l}1.29 \\
(1.11-1.47)\end{array}$ & $\begin{array}{l}1.69 \\
(1.48-1.93)\end{array}$ & $\begin{array}{l}2.23 \\
(1.94-2.64)\end{array}$ & $\begin{array}{l}3.41 \\
\quad(2.65-19.35)\end{array}$ & $\begin{array}{l}1.69 \\
\quad(0.21-19.35)\end{array}$ \\
\hline & No. of participants & 8,754 & 8,596 & 8,900 & 8,659 & 8,732 & 43,641 \\
\hline & Age, mean (SD), year & $38.2(7.5)$ & $39.1(7.1)$ & $39.8(6.8)$ & $40.2(6.5)$ & $40.7(6.1)$ & $39.6(6.9)$ \\
\hline & $\begin{array}{l}\text { Total cholesterol, mean } \\
(\mathrm{SD}) \\
(\mathrm{mmol} / \mathrm{l})\end{array}$ & $5.56(1.08)$ & $5.92(1.14)$ & $6.13(1.19)$ & $6.42(1.23)$ & $6.86(1.32)$ & $6.18(1.27)$ \\
\hline & $\begin{array}{l}\text { Systolic blood pressure, } \\
\text { mean (SD), (mm Hg) }\end{array}$ & $133(15)$ & $134(15)$ & $135(15)$ & $136(15)$ & $138(15)$ & $135(14.9)$ \\
\hline & $\begin{array}{l}\text { Diastolic blood pressure, } \\
\text { mean }(\mathrm{SD}),(\mathrm{mm} \mathrm{Hg})\end{array}$ & $81(11)$ & $82(11)$ & $82(11)$ & $83(11)$ & $85(11)$ & $82(11)$ \\
\hline & BMI, mean (SD), $\left(\mathrm{kg} / \mathrm{m}^{2}\right)$ & $23.8(2.6)$ & $24.3(2.6)$ & $24.7(2.8)$ & $25.3(2.9)$ & $26.5(3.2)$ & $24.9(3.0)$ \\
\hline & Smoking (\%) & 47.7 & 51.1 & 51.9 & 53.1 & 55.5 & 51.9 \\
\hline & Physical inactivity (\%) & 16.0 & 17.5 & 18.1 & 19.2 & 21.5 & 18.5 \\
\hline & $\begin{array}{l}\text { Time since meal, mean } \\
\text { (SD) }\end{array}$ & $2.77(1.10)$ & $2.51(1.06)$ & $2.38(1.02)$ & $2.29(1.00)$ & $2.26(0.98)$ & $2.44(1.05)$ \\
\hline
\end{tabular}

Abbreviations BMI body mass index, $S D$ standard deviation

SI conversion factors To convert triglycerides to $\mathrm{mg} / \mathrm{dl}$, divide values by 0.013 ; and cholesterol to $\mathrm{mg} / \mathrm{dl}$, divide values by 0.0259 
dilution are calculated as $\mathrm{HR}_{\mathrm{d}}=\exp (\ln \mathrm{HR} / \mathrm{R})$, where $\mathrm{HR}$ is the age-adjusted hazard ratio.

Statistical analyses were performed using STATA version 10.0 (STATA Corp. TX, USA).

\section{Results}

The study included 42,600 women and 43,641 men aged 20-50 years at inclusion, with a mean follow-up of 27.0 years (range $0.01-33.8$ ). Women had lower levels of triglycerides compared to men, medians (range) triglycerides were $1.13(0.21-18.72) \mathrm{mmol} / \mathrm{l}$ and 1.69 (0.21-19.35) mmol/l, respectively (Table 1). Mean age, total cholesterol, systolic and diastolic blood pressure, BMI, the proportions of smokers and physically inactive individuals increased over the quintiles for both women and men. The proportion of post-menopausal women also increased with increasing quintiles of triglycerides. The majority of the blood samples $(98.2 \%)$ were drawn less than $8 \mathrm{~h}$ after the last meal (data not shown), and can therefore be considered nonfasting samples. The levels of triglycerides were highest in the category measured less than $1 \mathrm{~h}$ after meal with a gradual decline thereafter (data not shown).

During follow-up, 5,267 women and 9,528 men died (Tables 2, 3). Of these, 1,296 women and 3,620 men died from CVD, 626 women and 2,408 men from IHD, and 360 women and 543 men from stroke. Mean age at death was 63.4 years (range 23.5-82.9). Mortality rates from all causes, CVD and IHD, increased over quintiles in both women and men, and from stroke in women only. In women the mortality rates were markedly higher in the fifth quintile. Significant interactions between triglycerides and gender were found for all endpoints, and all analyses were thus stratified by gender. In age-adjusted analyses, significant positive trends were found for all endpoints, except for stroke in men (Tables 2, 3). The estimated HRs were highest for CVD and IHD, and higher in women than men.

In multivariable analyses, the associations were attenuated in both women and men (Tables 2, 3). Significantly elevated HRs were found in women in the fifth quintile for all cause, CVD, and IHD deaths $(P$ for trend $<0.001)$ and for stroke ( $P$ for trend 0.03 ). In men the positive trend disappeared for all cause deaths after multivariable

Table 2 Association between triglycerides and risk of death from all causes, CVD, IHD, and stroke in 41,317 women in the main study sample (age 20-50 at baseline)

\begin{tabular}{|c|c|c|c|c|c|c|}
\hline & \multicolumn{5}{|c|}{ Quintile of nonfasting triglycerides, range $(\mathrm{mmol} / \mathrm{l})$} & \multirow[t]{2}{*}{$P$ for trend } \\
\hline & $\begin{array}{l}1 \\
0.21-0.79\end{array}$ & $\begin{array}{l}2 \\
0.80-1.01\end{array}$ & $\begin{array}{l}3 \\
1.02-1.27\end{array}$ & $\begin{array}{l}4 \\
1.28-1.70\end{array}$ & $\begin{array}{l}5 \\
1.71-18.72\end{array}$ & \\
\hline No. of participants & 8,343 & 8,082 & 8,350 & 8,385 & 8,157 & \\
\hline \multicolumn{7}{|l|}{ All cause deaths } \\
\hline No. of cases & 663 & 842 & 1,056 & 1,202 & 1,504 & \\
\hline Mortality per 1,000 person years & 2.9 & 3.8 & 4.6 & 5.2 & 6.9 & \\
\hline Age-adjusted HR (95\% CI) & 1.00 & $1.15(1.04-1.27)$ & $1.34(1.21-1.47)$ & $1.48(1.34-1.63)$ & $1.87(1.71-2.05)$ & $<0.001$ \\
\hline Multivariable HR $(95 \% \mathrm{CI})^{\mathrm{a}}$ & 1.00 & $1.06(0.96-1.18)$ & $1.17(1.06-1.30)$ & $1.24(1.13-1.37)$ & $1.42(1.28-1.57)$ & $<0.001$ \\
\hline \multicolumn{7}{|l|}{ CVD deaths } \\
\hline No. of cases & 110 & 204 & 233 & 280 & 469 & \\
\hline Mortality per 1,000 person years & 0.5 & 0.9 & 1.0 & 1.2 & 2.1 & \\
\hline Age-adjusted HR (95\% CI) & 1.00 & $1.61(1.28-2.03)$ & $1.69(1.35-2.12)$ & $1.95(1.56-2.43)$ & $3.27(2.66-4.03)$ & $<0.001$ \\
\hline Multivariable HR $(95 \% \mathrm{CI})^{\mathrm{a}}$ & 1.00 & 1.37 (1.09-1.73) & $1.28(1.02-1.61)$ & $1.34(1.07-1.68)$ & $1.77(1.41-2.21)$ & $<0.001$ \\
\hline \multicolumn{7}{|l|}{ IHD deaths } \\
\hline No. of cases & 47 & 92 & 97 & 136 & 254 & \\
\hline Mortality per 1,000 person years & 0.2 & 0.4 & 0.4 & 0.6 & 1.2 & \\
\hline Age-adjusted HR (95\% CI) & 1.00 & $1.70(1.20-2.42)$ & $1.65(1.16-2.33)$ & $2.23(1.60-3.10)$ & $4.17(3.05-5.70)$ & $<0.001$ \\
\hline Multivariable HR $(95 \% \mathrm{CI})^{\mathrm{a}}$ & 1.00 & $1.40(0.99-2.00)$ & $1.19(0.84-1.69)$ & $1.43(1.02-2.01)$ & $2.02(1.45-2.82)$ & $<0.001$ \\
\hline \multicolumn{7}{|l|}{ Stroke deaths } \\
\hline No. of cases & 34 & 62 & 74 & 81 & 109 & \\
\hline Mortality per 1,000 person years & 0.1 & 0.3 & 0.3 & 0.4 & 0.5 & \\
\hline Age-adjusted HR (95\% CI) & 1.00 & $1.63(1.07-2.48)$ & $1.80(1.20-2.70)$ & $1.90(1.27-2.84)$ & $2.58(1.75-3.79)$ & $<0.001$ \\
\hline Multivariable HR $(95 \% \mathrm{CI})^{\mathrm{a}}$ & 1.00 & $1.47(0.96-2.23)$ & $1.49(0.99-2.25)$ & $1.49(0.99-2.25)$ & $1.71(1.13-2.59)$ & 0.03 \\
\hline
\end{tabular}

Abbreviations $C I$ confidence interval, $C V D$ cardiovascular disease, $H R$ hazard ratio, $I H D$ Ischemic heart disease

a Adjusted for total cholesterol, systolic blood pressure, smoking, body mass index, menopausal status, time since meal, and physical activity 
Table 3 Association between triglycerides and risk of death from all causes, CVD, IHD, and stroke in 42,653 men in the main study sample (age $20-50$ at baseline)

\begin{tabular}{|c|c|c|c|c|c|c|}
\hline & \multicolumn{5}{|c|}{ Quintile of nonfasting triglycerides, range (mmol/l) } & \multirow[t]{2}{*}{$P$ for trend } \\
\hline & $\begin{array}{l}1 \\
0.21-1.10\end{array}$ & $\begin{array}{l}2 \\
1.11-1.47\end{array}$ & $\begin{array}{l}3 \\
1.48-1.93\end{array}$ & $\begin{array}{l}4 \\
1.94-2.64\end{array}$ & $\begin{array}{l}5 \\
2.65-19.35\end{array}$ & \\
\hline No. of participants & 8,548 & 8,386 & 8,689 & 8,477 & 8,553 & \\
\hline \multicolumn{7}{|l|}{ All cause deaths } \\
\hline No. of cases & 1,671 & 1,674 & 1,940 & 2,012 & 2,231 & \\
\hline Mortality per 1,000 person years & 7.3 & 7.4 & 8.4 & 9.1 & 10.2 & \\
\hline Age-adjusted HR (95\% CI) & 1.0 & $0.95(0.89-1.02)$ & $1.04(0.97-1.11)$ & $1.12(1.05-1.20)$ & $1.28(1.20-1.36)$ & $<0.001$ \\
\hline Multivariable HR $(95 \% \mathrm{CI})^{\mathrm{a}}$ & 1.0 & $0.89(0.83-0.96)$ & $0.94(0.88-1.00)$ & $0.96(0.90-1.03)$ & $0.99(0.92-1.06)$ & 0.43 \\
\hline \multicolumn{7}{|l|}{ CVD deaths } \\
\hline No. of cases & 533 & 582 & 703 & 801 & 1.001 & \\
\hline Mortality per 1.000 person years & 2.3 & 2.6 & 3.0 & 3.6 & 4.6 & \\
\hline Age-adjusted HR (95\% CI) & 1.00 & $1.04(0.92-1.16)$ & $1.17(1.05-1.31)$ & $1.39(1.25-1.55)$ & $1.78(1.61-1.98)$ & $<0.001$ \\
\hline Multivariable HR $(95 \% \mathrm{CI})^{\mathrm{a}}$ & 1.00 & $0.92(0.82-1.03)$ & $0.96(0.85-1.08)$ & $1.03(0.92-1.15)$ & $1.07(0.96-1.21)$ & 0.03 \\
\hline \multicolumn{7}{|l|}{ IHD deaths } \\
\hline No. of cases & 311 & 373 & 474 & 561 & 689 & \\
\hline Mortality per 1,000 person years & 1.4 & 1.7 & 2.0 & 2.5 & 3.2 & \\
\hline Age-adjusted HR (95\% CI) & 1.00 & $1.14(0.98-1.33)$ & $1.37(1.18-1.58)$ & $1.68(1.46-1.93)$ & $2.11(1.85-2.41)$ & $<0.001$ \\
\hline Multivariable HR $(95 \% \mathrm{CI})^{\mathrm{a}}$ & 1.00 & $1.00(0.86-1.16)$ & $1.09(0.94-1.26)$ & $1.20(1.04-1.39)$ & $1.21(1.05-1.40)$ & $<0.001$ \\
\hline \multicolumn{7}{|l|}{ Stroke deaths } \\
\hline No. of cases & 102 & 99 & 113 & 105 & 124 & \\
\hline Mortality per 1,000 person years & 0.4 & 0.4 & 0.5 & 0.5 & 0.6 & \\
\hline Age-adjusted HR (95\% CI) & 1.00 & $0.91(0.69-1.19)$ & $0.97(0.74-1.26)$ & $0.94(0.71-1.23)$ & $1.15(0.89-1.50)$ & 0.30 \\
\hline Multivariable HR $(95 \% \mathrm{CI})^{\mathrm{a}}$ & 1.00 & $0.85(0.64-1.12)$ & $0.86(0.66-1.13)$ & $0.79(0.59-1.05)$ & $0.86(0.65-1.15)$ & 0.30 \\
\hline
\end{tabular}

Abbreviations $C I$ confidence interval, $C V D$ cardiovascular disease, $H R$ hazard ratio, $I H D$ ischemic heart disease

a Adjusted for total cholesterol, systolic blood pressure, smoking, body mass index, time since meal, and physical activity

adjustment, but was still significant for CVD and IHD deaths ( $P$ for trend 0.03 and $<0.001$, respectively). No significant interactions were found between triglycerides and time since last meal, BMI, smoking, or cholesterol. No substantial deviations from the proportional hazards assumption were detected. The linearity assumption for triglycerides was met for most models, except in men for all cause and IHD deaths, and for CVD deaths in women.

Table 4 shows the change in the HR when adjusting individually for each of the three major risk factors, cholesterol, systolic blood pressure, and smoking. The relative increase in risk associated with an increase of $1 \mathrm{mmol} / \mathrm{l}$ triglyceride was higher in women than in men in both ageadjusted and multivariable analyses. Adjusting for confounders reduced the HRs, and in men cholesterol was the strongest confounder, whereas in women cholesterol, blood pressure and smoking similarly changed the estimates. Adjusting for regression dilution bias strengthens the effect estimates. For example for IHD in women, age-adjusted HR per $1 \mathrm{mmol} / \mathrm{l}$ triglyceride changes from 1.45 to 2.07 if we adjust for regression dilution bias. The estimates given in the tables are not adjusted for regression dilution bias.
The baseline characteristics of the sub-sample from screening II with HDL-measurements are given in Table 5. Mean follow-up was 24.8 years (range from 0.01 to 27.8). Due to the study design, mean age at screening (Table 5) and mean age at death was slightly higher in the sub-sample, i.e. 65.6 years (range 26.3-81.6). Women had higher HDL-cholesterol levels than men. Compared to the main study sample (Table 1), the subjects in the sub-sample smoked less and were more physically active. By comparing the different models with and without adjustment for HDL-cholesterol, we see that the effect of triglycerides is attenuated after adjustment, particularly in women (Table 6). Additionally, the previous differences between men and women were no longer present after inclusion of HDL-cholesterol in the models. There is still a significant effect of triglycerides on all cause mortality in both men and women, however, the association is considerably weaker after multivariable adjustment (Table 6), suggestion residual confounding. No significant interactions were found between triglycerides and HDL-cholesterol.

The Framingham CHD risk scores were significantly associated with risk of death from CVD and IHD (Table 7). 
Table 4 Risk of death from all causes, CVD, IHD, and stroke by a $1 \mathrm{mmol} / \mathrm{l}$ increase in nonfasting triglyceride levels in the main study sample (age 20-50 at baseline)

\author{
Abbreviations $C I$ confidence \\ interval, $C V D$ cardiovascular \\ disease, $I H D$ ischemic heart \\ disease \\ a Based on nonfasting \\ triglycerides on a continuous \\ scale \\ b Adjusted for total cholesterol, \\ systolic blood pressure, \\ smoking, body mass index, \\ menopausal status (women \\ only), time since meal, and \\ physical activity
}

\begin{tabular}{|c|c|c|}
\hline \multirow[t]{2}{*}{ Adjusted for age and: } & \multicolumn{2}{|l|}{ Hazard ratios $(95 \% \mathrm{CI})^{\mathrm{a}}$} \\
\hline & Women $(n=41,317)$ & Men $(n=42,653)$ \\
\hline All cause deaths & $n=5,267$ & $n=9,528$ \\
\hline None & $1.27(1.24-1.30)$ & $1.10(1.08-1.12)$ \\
\hline Total cholesterol (mmol/l) & $1.23(1.20-1.27)$ & $1.05(1.03-1.07)$ \\
\hline Systolic blood pressure $(\mathrm{mm} \mathrm{Hg})$ & $1.24(1.21-1.27)$ & $1.08(1.07-1.10)$ \\
\hline Smoking (yes/no) & $1.22(1.19-1.25)$ & $1.09(1.07-1.10)$ \\
\hline All three & $1.17(1.13-1.20)$ & $1.03(1.02-1.05)$ \\
\hline Full model ${ }^{\mathrm{b}}$ & $1.16(1.13-1.20)$ & $1.03(1.01-1.04)$ \\
\hline CVD deaths & $n=1,296$ & $n=3,620$ \\
\hline None & $1.40(1.35-1.45)$ & $1.17(1.15-1.19)$ \\
\hline Total cholesterol (mmol/l) & $1.34(1.28-1.39)$ & $1.08(1.06-1.11)$ \\
\hline Systolic blood pressure (mm $\mathrm{Hg}$ ) & $1.35(1.30-1.40)$ & $1.14(1.11-1.16)$ \\
\hline Smoking (yes/no) & $1.34(1.29-1.39)$ & $1.16(1.13-1.18)$ \\
\hline All three & $1.24(1.18-1.30)$ & $1.05(1.03-1.08)$ \\
\hline Full model $^{\mathrm{b}}$ & $1.20(1.14-1.27)$ & $1.03(1.00-1.05)$ \\
\hline IHD deaths & $n=626$ & $n=2,408$ \\
\hline None & $1.45(1.40-1.52)$ & $1.19(1.16-1.22)$ \\
\hline Total cholesterol (mmol/l) & $1.39(1.32-1.46)$ & $1.09(1.06-1.12)$ \\
\hline Systolic blood pressure $(\mathrm{mm} \mathrm{Hg})$ & $1.41(1.35-1.47)$ & $1.15(1.12-1.18)$ \\
\hline Smoking (yes/no) & $1.40(1.34-1.46)$ & $1.17(1.14-1.20)$ \\
\hline All three & $1.29(1.22-1.36)$ & $1.05(1.03-1.08)$ \\
\hline Full model ${ }^{\mathrm{b}}$ & $1.26(1.19-1.34)$ & $1.03(1.00-1.06)$ \\
\hline Stroke deaths & $n=360$ & $n=543$ \\
\hline None & $1.27(1.15-1.40)$ & $1.07(1.00-1.14)$ \\
\hline Total cholesterol (mmol/l) & $1.22(1.09-1.36)$ & $1.03(0.96-1.11)$ \\
\hline Systolic blood pressure (mm $\mathrm{Hg}$ ) & $1.22(1.10-1.35)$ & $1.04(0.98-1.11)$ \\
\hline Smoking (yes/no) & $1.21(1.09-1.34)$ & $1.06(1.00-1.13)$ \\
\hline All three & $1.12(0.99-1.26)$ & $1.01(0.94-1.08)$ \\
\hline Full model $^{\mathrm{b}}$ & $1.09(0.96-1.23)$ & $0.99(0.92-1.07)$ \\
\hline
\end{tabular}

The hazard ratio was unchanged after adjustment for triglycerides, and triglycerides had no predictive value after inclusion of the Framingham score in the model.

\section{Discussion}

In the Norwegian Counties Study nonfasting triglycerides were positively associated with CVD death in both genders, with hazard ratios being higher in women than in men. After adjustment for cholesterol, systolic blood pressure and smoking, and in a sub sample also HDLcholesterol, the associations were distinctly attenuated. After adjustment for the Framingham risk score, the positive association between triglycerides and mortality risk disappeared.

Recent reports from two prospective studies have described strong associations between postprandial triglycerides and risk of CVD and stroke [7-9]. The Copenhagen City Heart Study showed an independent effect of nonfasting triglycerides on myocardial infarction, IHD, and stroke, particularly in women [8, 9]. Accordingly, in the Women's Health Study nonfasting, but not fasting, levels were associated with incident cardiovascular events in females [7]. In the Copenhagen City Heart Study, the main analyses were not adjusted for HDL-cholesterol, and thus are comparable to our analyses on the total study sample. For example for all cause deaths in women the ageadjusted HRs per $1 \mathrm{mmol} / \mathrm{l}$ increase in triglycerides were 1.27 and 1.26 in ours and the Danish study, respectively. After multivariable adjustment the corresponding HRs were 1.16 and 1.18. Comparable estimates were also found for IHD and CVD. In the Women's Health Study, on the other hand, the association between triglycerides and risk still persisted after adjustment for additional risk factors including HDL-cholesterol [7]. Discrepancies between univariate and multivariable analyses in studies on CVD risk and triglycerides have been reported in many studies $[4,7,8]$. Due to the strong negative correlation between HDL-cholesterol and triglycerides, and to the differences in 
Table 5 Baseline [Baseline values are data from attendance at screening II] characteristics of the sub sample with HDLcholesterol from screening II (age 20-55 at baseline)

Abbreviations BMI body mass index, $H D L$ high density lipoprotein, $S D$ standard deviation

Table 6 Risk of death from all causes, CVD, IHD, and stroke by a $1 \mathrm{mmol} / \mathrm{l}$ increase in nonfasting triglyceride levels in the sub sample with HDLcholesterol from screening II (age 20-55 at baseline)

\author{
Abbreviations CI confidence \\ interval, $C V D$ cardiovascular \\ disease, $H D L$ high density \\ lipoprotein, $I H D$ ischemic heart \\ disease \\ ${ }^{\text {a }}$ Based on nonfasting \\ triglycerides on a continuous \\ scale \\ b Multivariable adjustments for \\ total cholesterol, HDL- \\ cholesterol, systolic blood \\ pressure, smoking, body mass \\ index, menopausal status \\ (women only), time since meal, \\ and physical activity
}

\begin{tabular}{llc}
\hline & Women $(n=20,293)$ & Men $(n=19,850)$ \\
\hline Age, mean (SD) & $44.7(7.3)$ & $44.6(7.4)$ \\
Triglycerides, mean (SD), (mmol/l) & $1.41(0.78)$ & $2.07(1.14)$ \\
Total cholesterol, mean (SD), (mmol/l) & $6.02(1.19)$ & $6.00(1.11)$ \\
HDL-cholesterol, mean (SD), (mmol/l) & $1.43(0.34)$ & $1.18(0.31)$ \\
Systolic blood pressure, mean (SD), (mm Hg) & $131(18)$ & $137(16)$ \\
BMI, mean (SD), (kg/m $\left.{ }^{2}\right)$ & $24.4(3.8)$ & $25.2(3.0)$ \\
Post-menopausal (\%) & 26.8 & - \\
Smoking (\%) & 33.6 & 44.7 \\
Physical inactivity (\%) & 14.9 & 13.7 \\
Time since meal, mean (SD) & $2.56(0.92)$ & $2.39(1.01)$ \\
\hline
\end{tabular}

\begin{tabular}{|c|c|c|}
\hline \multirow[t]{2}{*}{ Adjusted for age and: } & \multicolumn{2}{|l|}{ Hazard ratios $(95 \% \mathrm{CI})^{\mathrm{a}}$} \\
\hline & Women $(n=20,293)$ & Men $(n=19,850)$ \\
\hline All cause deaths & $n=2,827$ & $n=4,747$ \\
\hline None & $1.19(1.15-1.24)$ & $1.10(1.08-1.13)$ \\
\hline HDL-cholesterol (mmol/l) & $1.15(1.10-1.20)$ & $1.11(1.08-1.13)$ \\
\hline Cholesterol, systolic blood pressure, and smoking & $1.11(1.06-1.16)$ & $1.06(1.03-1.08)$ \\
\hline All four & $1.07(1.02-1.12)$ & $1.06(1.03-1.09)$ \\
\hline Full model ${ }^{\mathrm{b}}$ & $1.06(1.01-1.12)$ & $1.06(1.03-1.09)$ \\
\hline CVD deaths & $n=709$ & $n=1,734$ \\
\hline None & $1.37(1.28-1.46)$ & $1.21(1.17-1.26)$ \\
\hline HDL-cholesterol (mmol/1) & $1.25(1.16-1.35)$ & $1.18(1.14-1.23)$ \\
\hline Cholesterol, systolic blood pressure, and smoking & $1.19(1.10-1.28)$ & $1.12(1.08-1.16)$ \\
\hline All four & $1.06(0.97-1.16)$ & $1.07(1.03-1.12)$ \\
\hline Full model $^{\mathrm{b}}$ & $1.03(0.94-1.13)$ & $1.06(1.01-1.11)$ \\
\hline IHD deaths & $n=344$ & $n=1,143$ \\
\hline None & $1.44(1.32-1.57)$ & $1.24(1.19-1.29)$ \\
\hline HDL-cholesterol (mmol/l) & $1.29(1.16-1.43)$ & $1.18(1.13-1.24)$ \\
\hline Cholesterol, systolic blood pressure, and smoking & $1.20(1.09-1.33)$ & $1.12(1.07-1.17)$ \\
\hline All four & $1.02(0.90-1.15)$ & $1.04(0.99-1.09)$ \\
\hline Full model $^{\mathrm{b}}$ & $0.99(0.88-1.13)$ & $1.03(0.97-1.08)$ \\
\hline Stroke deaths & $n=195$ & $n=278$ \\
\hline None & $1.33(1.17-1.51)$ & $1.07(0.97-1.19)$ \\
\hline HDL-cholesterol (mmol/l) & $1.19(1.02-1.39)$ & $1.07(0.96-1.19)$ \\
\hline Cholesterol, systolic blood pressure, and smoking & $1.23(1.07-1.42)$ & $1.05(0.95-1.17)$ \\
\hline All four & $1.10(0.92-1.30)$ & $1.04(0.93-1.17)$ \\
\hline Full model $^{\mathrm{b}}$ & $1.10(0.92-1.31)$ & $1.05(0.93-1.18)$ \\
\hline
\end{tabular}

the measurement variability of these lipids, it has been shown theoretically that by adjusting for HDL-cholesterol, the triglyceride-disease association will be consistently underestimated [4]. It is thus controversial whether HDLcholesterol should be included in multivariable models, as also discussed in the two prospective studies described above [7, 8].

It has been difficult to demonstrate a possible causal relationship between triglycerides and CVD by drug intervention studies, as drugs that reduce triglycerides also raise HDL-cholesterol [20]. Interestingly, a recent paper addresses the question of causality by studying a genetic polymorphism regulating triglyceride concentration [24]. The results from this collaborative analysis of 101 studies indicate a causal association between triglyceride-mediated pathways and coronary heart disease. Previous meta-analyses report an increase in CHD risk of about $70 \%$ comparing high triglyceride levels with low triglyceride levels 
Table 7 Risk of death from CVD and IHD in the sub sample with calculated Framingham risk score from screening II (age $40-55$ at baseline)

Abbreviations CI confidence interval, $C V D$ cardiovascular disease, $I H D$ ischemic heart disease

${ }^{\text {a }}$ Based on nonfasting triglycerides on a continuous scale

All models adjusted for age

\begin{tabular}{|c|c|c|}
\hline & \multicolumn{2}{|c|}{ Hazard ratios $(95 \% \mathrm{CI})^{\mathrm{a}}$} \\
\hline & $\begin{array}{l}\text { One variable at } \\
\text { a time in model }\end{array}$ & $\begin{array}{l}\text { Both variables } \\
\text { in model }\end{array}$ \\
\hline \multicolumn{3}{|l|}{ Women $(n=16,805)$} \\
\hline \multicolumn{3}{|l|}{ CVD deaths $(n=691)$} \\
\hline Triglycerides (per $1 \mathrm{mmol} / \mathrm{l}$ ) & $1.36(1.28-1.46)$ & $0.97(0.89-1.06)$ \\
\hline Framingham (per 1 unit) & $1.11(1.10-1.12)$ & $1.11(1.10-1.13)$ \\
\hline \multicolumn{3}{|l|}{ IHD deaths $(n=335)$} \\
\hline Triglycerides (per $1 \mathrm{mmol} / \mathrm{l}$ ) & $1.43(1.31-1.56)$ & $0.96(0.85-1.08)$ \\
\hline Framingham (per 1 unit) & $1.13(1.11-1.14)$ & $1.13(1.11-1.15)$ \\
\hline \multicolumn{3}{|l|}{$\operatorname{Men}(n=16,318)$} \\
\hline \multicolumn{3}{|l|}{ CVD deaths $(n=1,657)$} \\
\hline Triglycerides (per $1 \mathrm{mmol} / \mathrm{l}$ ) & $1.22(1.18-1.26)$ & $1.02(0.98-1.07)$ \\
\hline Framingham (per 1 unit) & $1.08(1.07-1.08)$ & $1.08(1.07-1.08)$ \\
\hline \multicolumn{3}{|l|}{ IHD deaths $(n=1,092)$} \\
\hline Triglycerides (per $1 \mathrm{mmol} / \mathrm{l}$ ) & $1.25(1.19-1.29)$ & $1.01(0.96-1.07)$ \\
\hline Framingham (per 1 unit) & $1.09(1.08-1.10)$ & $1.09(1.08-1.10)$ \\
\hline
\end{tabular}

$[2,3]$. However, it is probably not the nonfasting triglycerides per se that cause atherosclerosis, but rather the cholesterol content of remnant lipoproteins [8, 21]. Remnant lipoproteins arise after lipolysis of chylomicrons and VLDL, the two classes of lipoproteins whose major lipid is triglyceride [22]. The remnant particles are under normal conditions rapidly taken up by the liver [22]. Hepatic removal of the remnant particles are, however, a complex process, and in people with a predisposition of producing remnant particles or small dense LDL and HDL particles, people with metabolic syndrome or type 2 diabetes, hepatic clearance of remnant particles can be delayed [8, 22, 23]. Thus, prolonged exposure of increased levels of circulating remnant particles will enhance the possibility for the particles to be entrapped in the arterial wall. Accordingly, remnant lipoproteins have been shown to increase risk of atherosclerotic heart disease [23]. A strong correlation between nonfasting triglycerides levels and remnant lipoprotein cholesterol has been shown [8], and this may account for the stronger associations of nonfasting levels of triglycerides with CVD [7]. One cannot exclude, however, that the association between nonfasting triglycerides levels and cardiovascular risk observed in our and previous studies in part could be a result of residual confounding by unmeasured confounders.

The finding of stronger effects of nonfasting triglycerides among women than men in our and previous studies $[8,9,11]$, are not easily explained. A gender dependent difference in risk has also been shown for fasting triglycerides [1, 4, 25], however, data are not consistent [2, 3].

The Framingham risk score includes HDL-cholesterol [18], and adjusting for HDL-cholesterol or the Framingham risk score attenuated the effect of triglycerides in the present study. Accordingly, a recent study including data from 112 prospective studies concluded that lipid assessment could be simplified by measurement of nonfasting lipids, either total cholesterol and HDL-cholesterol or apolipoproteins, without regard to triglycerides [26]. Thus the role for triglycerides as an independent risk factor is still controversial.

The Norwegian Counties Study has several strengths. First, the mortality in the three counties under study, were found to be similar to the national levels [27], and as the attendance was high (84-88\%), we argue that this study sample is representative of Norway. Our study sample is of considerable size, and has a long and complete follow-up. It is noted that the power to detect a hazard ratio of 1.06 at the $5 \%$ level, varies from $>0.9$ in men (all cause deaths) to 0.2 in women (stroke deaths). For IHD deaths the power is 0.6 in women and 0.9 in men. Thus, for some endpoints, we have sufficient power to reveal even small effects.

A major limitation is that we do not have data on exposure after 1988. Due to the long follow-up time, a considerable number of individuals might have started with medications affecting triglycerides levels. We could not adjust for alcohol or hormone therapy, however, no differences in CVD mortality between users and non-users of hormone therapy have previously been reported in women from screening III [28].

In summary, we observed a stronger association between nonfasting triglycerides and risk of cardiovascular death in women than in men. The effect, was, however, attenuated after adjustment for HDL-cholesterol or adjustment for Framingham risk. Lastly, nonfasting triglycerides add no predictive information of CVD risk beyond the Framingham CHD risk score. 
Acknowledgments We thank the participants, the staff at the former National Health Screening Service in Oslo, and the Department of Community Medicine, University of Troms $\emptyset$ for carrying out the screenings.

Funding This work was supported by a grant to A.S. Lindman by the Norwegian Research Council, www.forskningsraadet.no [grant number 165775].

\section{Conflict of interest None declared.}

Open Access This article is distributed under the terms of the Creative Commons Attribution Noncommercial License which permits any noncommercial use, distribution, and reproduction in any medium, provided the original author(s) and source are credited.

\section{References}

1. Hokanson JE, Austin MA. Plasma triglyceride level is a risk factor for cardiovascular disease independent of high-density lipoprotein cholesterol level: a meta-analysis of population-based prospective studies. J Cardiovasc Risk. 1996;3:213-9.

2. Sarwar N, Danesh J, Eiriksdottir G, Sigurdsson G, Wareham N, Bingham S, Boekholdt SM, Khaw KT, Gudnason V. Triglycerides and the risk of coronary heart disease-10,158 incident cases among 2,62,525 participants in 29 Western prospective studies. Circulation. 2007;115:450-8.

3. Patel A, Barzi F, Jamrozik K, Lam TH, Ueshima H, Whitlock G, Woodward M. Serum triglycerides as a risk factor for cardiovascular diseases in the Asia-Pacific region. Circulation. 2004; 110:2678-86.

4. Austin MA. Plasma triglyceride and coronary heart disease. Arterioscler Thromb. 1991;11:2-14.

5. Zilversmit DB. Atherogenesis: a postprandial phenomenon. Circulation. 1979;60:473-85.

6. Kolovou GD, Anagnostopoulou KK, Daskalopoulou SS, Mikhailidis DP, Cokkinos DV. Clinical relevance of postprandial lipaemia. Curr Med Chem. 2005;12:1931-45.

7. Bansal S, Buring JE, Rifai N, Mora S, Sacks FM, Ridker PM. Fasting compared with nonfasting triglycerides and risk of cardiovascular events in women. JAMA. 2007;298:309-16.

8. Nordestgaard BG, Benn M, Schnohr P, Tybjaerg-Hansen A. Nonfasting triglycerides and risk of myocardial infarction, ischemic heart disease, and death in men and women. JAMA. 2007;298:299-308.

9. Freiberg JJ, Tybjaerg-Hansen A, Jensen JS, Nordestgaard BG. Nonfasting triglycerides and risk of ischemic stroke in the general population. JAMA. 2008;300:2142-52.

10. Bravo E, Napolitano M. Mechanisms involved in chylomicron remnant lipid uptake by macrophages. Biochem Soc Trans. 2007;35:459-63.

11. Stensvold I, Tverdal A, Urdal P, Graff-Iversen S. Non-fasting serum triglyceride concentration and mortality from coronary heart disease and any cause in middle aged Norwegian women. BMJ. 1993;307:1318-22.
12. Tverdal A, Foss OP, Leren P, Holme I, Lundlarsen PG, Bjartveit K. Serum triglycerides as an independent risk factor for death from coronary heart-disease in middle-aged Norwegian men. Am J Epidemiol. 1989;129:458-65.

13. The cardiovascular surveys in Finnmark, Sogn og Fjordane and Oppland. 1974-78, 1977-83 and 1985-88. http://www.fhi.no/ dav/864a41442b.doc. Accessed 21 Dec 2009.

14. Bjartveit K, Foss OP, Gjervig T, Lund-Larsen PG. The cardiovascular disease study in Norwegian counties. Background and organization. Acta Med Scand Suppl. 1979;634:1-70.

15. Bjartveit K, Foss OP, Gjervig T. The cardiovascular disease study in Norwegian counties. Results from first screening. Acta Med Scand Suppl. 1983;675:1-184.

16. National Health Screening Service, Health Surveys of Finnmark, Sogn og Fjordane, and Oppland counties, Ullevål Hospital, Central laboratory, Oslo. The cardiovascular disease study in Norwegian counties. Results from second screening. Oslo: National Health Screening Service; 1988.

17. Stensvold I, Urdal P, Thürmer H, Tverdal A, Lund-Larsen PG, Foss OP. High-density-lipoprotein cholesterol and coronary, cardiovascular and all cause mortality among middle-aged Norwegian men and women. Eur Heart J. 1992;13:1155-63.

18. Anderson KM, Odell PM, Wilson PW, Kannel WB. Cardiovascular disease risk profiles. Am Heart J. 1991;121:293-8.

19. Clarke R, Shipley M, Lewington S, Youngman L, Collins R, Marmot M, Peto R. Underestimation of risk associations due to regression dilution in long-term follow-up of prospective studies. Am J Epidemiol. 1999;150:341-53.

20. Ferns G, Keti V, Griffin B. Investigation and management of hypertriglyceridaemia. J Clin Pathol. 2008;61:1174-83.

21. Stalenhoef AF, de Graaf J. Association of fasting and nonfasting serum triglycerides with cardiovascular disease and the role of remnant-like lipoproteins and small dense LDL. Curr Opin Lipidol. 2008;19:355-61.

22. Ginsberg HN. New perspectives on atherogenesis: role of abnormal triglyceride-rich lipoprotein metabolism. Circulation. 2002;106:2137-42.

23. Tabas I, Williams KJ, Boren J. Subendothelial lipoprotein retention as the initiating process in atherosclerosis: update and therapeutic implications. Circulation. 2007;116:1832-44.

24. Triglyceride Coronary Disease Genetics Consortium and Emerging Risk Factors Collaboration. Triglyceride-mediated pathways and coronary disease: collaborative analysis of 101 studies. Lancet. 2010;375:1634-9.

25. Austin MA. Triacylglycerol and coronary heart disease. Proc Nutr Soc. 1997;56:667-70.

26. Di Angelantonio E, Sarwar N, Perry P, Kaptoge S, Ray KK, Thompson A, Wood AM, Lewington S, Sattar N, Packard CJ, Collins R, Thompson SG, Danesh J. Major lipids, apolipoproteins, and risk of vascular disease. JAMA. 2009;302:1993-2000.

27. Vollset SE, Selmer R, Tverdal A, Gjessing H. Mortality from smoking in Norway. Norwegian Institute of Public Health; 2006. (ISBN: 82-8082-163-5, electronic version).

28. Graff-Iversen S, Hammar N, Thelle DS, Tonstad S. Hormone therapy and mortality during a 14-year follow-up of 14,324 Norwegian women. J Intern Med. 2004;256:437-45. 